\title{
Estimativa do estoque da população apta a demandar por educação de jovens e adultos no Estado de São Paulo em 1995 e 2015*
}

\author{
Flávia Vitor Longo * \\ Joice Melo Vieira ${ }^{\star * \star}$
}

\begin{abstract}
A Lei de Diretrizes e Bases da Educação Nacional estabelece que é dever da Federação recensear anualmente não apenas crianças e adolescentes em idade escolar, mas também os jovens e adultos que não concluíram a educação básica. 0 objetivo deste estudo é mensurar o estoque de jovens e adultos (15 a 64 anos) com educação básica incompleta no Estado de São Paulo e estimar a demanda por nível de ensino se todos eles retornassem aos bancos escolares. A metodologia fundamenta-se em dados da Pesquisa Nacional por Amostra de Domicílios de 1995 e 2015 e na aplicação do modelo Profluxo. Os resultados indicam que os principais gargalos do sistema estão na passagem de um ciclo educacional para outro. A demanda por Educação de Jovens e Adultos (EJA) persiste, especialmente nos primeiros anos de cada ciclo da educação básica, ainda que em menor volume em 2015 se comparado a 1995.
\end{abstract}

Palavras-chave: Estado de São Paulo. Políticas públicas de educação. Educação de Jovens e Adultos (EJA). Pesquisa Nacional por Amostra de Domicílios (PNAD). Profluxo.

\footnotetext{
* 0 presente artigo é um produto da tese de doutorado Demografia e políticas educacionais: um olhar sobre a proposta da reorganização escolar paulista de 2015, de autoria de Flávia Vitor Longo dos Santos, defendida junto ao Programa de Pós-Graduação em Demografia/Unicamp e que contou com apoio da Coordenação de Aperfeiçoamento de Pessoal de Nível Superior - Brasil (Capes), processo n. 150615.

** Universidade Estadual de Campinas (Unicamp), Campinas-SP, Brasil (longo.fla@gmail.com; https://orcid.org/00000003-1818-3899).

*** Universidade Estadual de Campinas (Unicamp), Núcleo de Estudos de População “Elza Berquó” (Nepo), Campinas-SP, Brasil (joicemv@unicamp.br; https://orcid.org/0000-0003-1625-6994).
} 


\section{Introdução}

Ao longo do desenvolvimento dos Estados modernos, a necessidade de estabelecer critérios amplos e impessoais que permitissem operacionalizar a organização e o controle social levou à crescente normatização etária. É nesse contexto que emergem visões tradicionais sobre o ciclo de vida humano dividido em três grandes fases: infância/adolescência, vida adulta e velhice (CAMARANO et al. 2006). A centralidade do trabalho e da produção como definidores do lugar a ser ocupado pelos indivíduos na estrutura social favoreceu a institucionalização da educação escolar como preparatória para o trabalho e dirigida ao atendimento de crianças e adolescentes. Enquanto o mundo do trabalho propriamente dito pertenceria por definição aos adultos, a velhice estaria associada à aposentadoria, uma etapa final do ciclo vital marcada pelo não trabalho.

Em decorrência dessa segmentação da vida e do que é atrelado a cada uma de suas fases, grande parte das políticas educacionais brasileiras e da legislação que lhe dá sustentação tem como foco principal crianças e adolescentes. No entanto, especialmente a partir da Constituição Federal de 1988, a educação é concebida como direito de todos e paulatinamente foram realizadas alterações que, ao menos do ponto de vista legal, reconhecem a importância da educação de jovens e adultos e buscam fortalecê-la. Segundo Graciano e Lugli (2017), as principais indicações de mudança de perspectiva incluem a fixação de financiamento específico para a educação de jovens e adultos, a inclusão deles em programas que facilitam o acesso a livros didáticos, merenda escolar e transporte, bem como a extensão dessa modalidade de ensino a pessoas reclusas no sistema prisional.

No inciso I do artigo 208 da Constituição Federal de 1988 está previsto que

O dever do Estado com a educação será efetivado mediante a garantia de: I - educação básica obrigatória e gratuita dos 4 (quatro) aos 17 (dezessete) anos de idade, assegurada inclusive sua oferta gratuita para todos os que a ela não tiveram acesso na idade própria. (BRASIL, 1988)

0 mesmo artigo, inciso VII, parágrafo $3^{\circ}$, estabelece que é responsabilidade do poder público recensear os educandos no ensino fundamental. 0 recenseamento de jovens e adultos que não tiveram acesso à educação básica, por sua vez, está previsto na Lei de Diretrizes e Bases da Educação Nacional, Lei n. 9.394 de 1996, artigo 5oㅡ, parágrafo 1ํㅡ, inciso I (BRASIL, 1996). De acordo com a redação dada a esse artigo pela Lei n. 12.796, de 2013, compete à Federação "recensear anualmente as crianças e adolescentes em idade escolar, bem como os jovens e adultos que não concluíram a educação básica” (BRASIL, 2013). Embora o Censo Escolar seja realizado anualmente pelo Instituto Nacional de Estudos e Pesquisas Educacionais Anísio Teixeira (Inep), ele se restringe às pessoas que estão inseridas no sistema educacional. Logo, a população em idade escolar obrigatória será mais bem coberta pelo Censo Escolar, enquanto um recenseamento anual dos que estão fora do sistema é condição fundamental para o planejamento de políticas educacionais voltadas para o público da Educação de Jovens e Adultos (EJA). 
A ausência de estimativas de demanda e a falta de indicadores de monitoramento de políticas voltadas para a educação de jovens e adultos são lacunas comumente apontadas em pesquisas sobre esse tipo de ensino (MACHADO, 2009; PIERRO, 2010; IRELAND, 2012, 2019; PIERRO, HADDAD, 2015; CASSIO et al., 2016). Procurando contribuir com esse campo, o objetivo do presente estudo é estimar a demanda pela modalidade EJA no estado de São Paulo. Quantas pessoas em idade ativa (15-64 anos) não concluíram a educação básica ou sequer ingressaram no sistema escolar? Esta é uma pergunta que visa estimar a parcela da população em idade ativa que ficou à margem do direito à educação básica. Pode-se argumentar que, diferentemente das crianças e adolescentes em idade escolar, grupo para o qual se considera que a demanda é idêntica ao tamanho da população de 4 a 17 anos, mensurar a demanda da EJA é mais complexo, pois retomar os estudos depende, nesse caso, da vontade individual. A possibilidade de as pessoas obterem certificados escolares mediante aprovação em exames próprios para esse fim também confere especificidade, pois pode não ser do interesse do indivíduo frequentar escola nos moldes tradicionais. Se o número de matrículas na EJA diminui ao longo do tempo, o número de inscrições em exames nacionais de certificação escolar segue trajetória inversa. Porém, os índices de aprovação por essa via são baixos - cerca de 10\% em 2013 para o nível médio - e muito seletivos, posto que beneficiam principalmente pessoas que estiveram afastadas da escola por pouco tempo (PIERRO; CATELLI JR., 2017). Seguindo o espírito da lei nacional, Graciano e Lugli (2017) argumentam que o recenseamento dos jovens e adultos que não concluíram a educação básica se faz necessário para que o Estado conheça quem são e quantos são aqueles que deveriam ser alvo de chamada pública para a EJA. Ou seja, equivocam-se aqueles que supõem que a demanda por EJA deva ser totalmente "espontânea". A partir da perspectiva da educação como direito de todos, deveria se tratar também de uma demanda estimulada pelo próprio Estado.

Utilizando a Pesquisa Nacional por Amostra de Domicílios (PNAD) como fonte de dados para elaboração do modelo Profluxo (FLETCHER; RIBEIRO, 1989), este trabalho quantifica o estoque da população de 15 a 64 anos sem escolaridade ou com educação básica incompleta, residente no estado de São Paulo em 1995 e em 2015, bem como as idades e anos/ séries que se configuram como mais críticos, quando se nota maior abandono escolar ou retenção no sistema educativo.

Escolheu-se São Paulo porque nesse estado, em 2015, foi implementada uma reorganização da rede escolar estadual, que previa o fechamento de escolas com base em argumentos pedagógicos e demográficos (PANTOJO et al., 2015; SEADE, 2015; SÃO PAULO, 2015). A política foi focalizada nas idades de 6 a 17 anos, correspondentes aos ciclos regulares dos ensinos fundamental e médio e não considerou o público de EJA. A oferta de EJA, por sua vez, é de responsabilidade de municípios (ensino fundamental) e estados (ensinos médio e médio profissionalizante). Desse modo, a Secretaria Estadual de Educação de São Paulo, ao desconsiderar a oferta de EJA na reorganização e no fechamento das escolas, além de reforçar a noção de ser esta uma educação de menor importância (MACHADO, 2009; PIERRO, 
HADDAD, 2010), sinaliza também diminuição da oferta, sobretudo na etapa correspondente ao ensino médio. A questão se torna sensível, pois, apesar da já documentada redução da participação da rede estadual na oferta desse tipo de atendimento, em 2015 ela era responsável por $57 \%$ do atendimento de EJA presencial, semipresencial e a distância, $11 \%$ do ensino fundamental do EJA Educação Especial (em 2010 eram 80\%) e 83\% do ensino médio nessa categoria (em 2010 eram 90\%) (PIERRO et al., 2017). Ao não ser considerada essa modalidade, mais uma vez o público por ela atendido corre o risco de não conseguir concluir a educação básica, seja pela diminuição da oferta de vagas, seja pela dificuldade de deslocamento a uma escola com oferta desse ensino.

A escolha da faixa etária de 15 a 64 anos justifica-se por dois motivos. Primeiro, porque 15 anos é a idade mínima para se matricular no EJA ensino fundamental (BRASIL, 2000). Segundo, porque essa é a faixa etária que corresponde à classificação arbitrária da População em Idade Ativa (PIA), o que permite conhecer o déficit educacional na população com idade teoricamente apta a compor a força de trabalho.

Quanto à escolha dos anos das PNAD, o de 1995 justifica-se pelo fato de a década de 1990 ter testemunhado a chamada "onda jovem” (BERCOVICH; MADEIRA, 1990), caracterizada pelo aumento abrupto da população no grupo etário de 15 a 24 anos e o consequente crescimento da demanda escolar desacompanhado da oferta, notadamente nas séries do ensino médio (CORTI, 2015). 0 ano de 2015 foi escolhido tanto pelo marco da política da reorganização escolar quanto por ser este o último ano da série temporal da PNAD, o que permite a comparação com 1995.

A questão da oferta de ensino para idades consideradas não escolares, como já sugerido até aqui, dialoga com pelos menos dois eixos teóricos. Um deles é o de curso de vida e o uso das idades enquanto marcadores definidores das etapas da vida e dos papéis a serem desempenhados em cada uma dessas etapas (CHAMBOREDON, 1985; SHEEHY, 1995; MOTTA, 1998; DEBERT, 1999; MACMILLAN, 2005; CAMARANO, 2016). Outro é o do campo das políticas públicas, marcos regulatórios, leis e documentos acerca do que se entende por educação como direito fundamental mesmo na fase adulta da vida, e os mecanismos de operacionalização dos conceitos e implementação de ações (MACHADO, 2009; PIERRO, 2010; MORAES, 2013; IRELAND, 2019). Com essas duas dimensões em perspectiva, procuramos no tópico seguinte contextualizar a discussão sobre a educação de adultos, especialmente a EJA, e a importância das estimativas da demanda por esse tipo de ensino.

\section{As idades da vida e a educação como direito fundamental}

Pesquisar sobre o acesso à educação entre a população adulta apoia-se na abordagem de curso de vida por subverter a lógica de que educação, como sinônimo de instrução e escolarização, esteja centrada nas fases da infância e juventude (MACMILLAN, 2005). Tanto o nível de escolaridade quanto a formação profissional não são atributos estanques e imutáveis. E ainda que os retornos dos investimentos em diferentes tipos de educação 
sejam também diferentes em cada etapa da vida, a capacidade cognitiva de aprendizagem permanece ao longo de toda a vida (FRITH, 2013).

A fase adulta da vida humana é delimitada por marcadores biológicos, pela idade cronológica e pelas atividades esperadas nessa etapa da vida, tais como formação de família e inserção no mundo do trabalho (CAMARANO, 2016). Embora a idade cronológica tenha sido empregada para definir as responsabilidades ao longo da vida desde o século XVIII (SHEEHY, 1995), foi somente com o advento do modo de produção capitalista-fordista que as fronteiras entre as etapas da vida passaram a ser mais bem delimitadas (MOTTA, 1998). Debert (1999) indica que foi nesse momento que se associou infância e juventude à escolarização, vida adulta ao mundo do trabalho e à produtividade econômica e velhice à aposentadoria. Os eventos que marcavam as transições entre as fases da vida, tais como a transição da escola ao mercado de trabalho, ou a saída da casa dos pais para formação de nova família, ocorriam nas mesmas idades para grande parte das pessoas (timing) e tendiam a ocorrer em uma mesma ordem (linearidade) até meados dos anos 1970 (SHEEHY, 1995), quando a lógica fordista começou a dar sinais de desgaste. As fronteiras etárias associadas às fases da vida, antes delineadas, passam a perder a nitidez de seus contornos. No entanto, a idade cronológica nem sempre foi vista como um critério óbvio ou legítimo para a atribuição de direitos e deveres de acordo com as fases da vida. Segundo Debert (1999, p. 73):

[A história das sociedades ocidentais contemporâneas] estaria marcada por três etapas sucessivas, em que a sensibilidade investida na idade cronológica é radicalmente distinta: a pré-modernidade em que a idade cronológica seria menos relevante do que o status da família na determinação do grau de maturidade e no controle de recursos de poder; a modernidade, que teria correspondido a uma cronologização da vida; e a pós-modernidade, que operaria uma desconstrução do curso da vida em nome de um estilo unietário.

O Estado, ao definir a idade escolar, opera a partir de uma lógica de cronologização ou padronização do curso de vida: entende que há uma fase da vida considerada ideal para que determinados eventos aconteçam (CHAMBOREDON, 1985, MACMILLAN, 2005). De acordo com a racionalidade moderna, tipicamente associada ao processo de industrialização, a infância e a adolescência se caracterizam pela dedicação exclusiva ao processo de formação socioemocional e educacional; a vida adulta é centrada na produção, sendo esperado que concomitantemente ocorra a reprodução biológica; e, por fim, chega-se à velhice, período associado à aposentadoria/inatividade no mercado de trabalho. No entanto, a emergência das sociedades pós-fordistas ou pós-modernas rompe com o caráter linear dos eventos ao longo da vida (DEBERT, 1999; MACMILLAN, 2005) e abala a relação entre idade e atividades esperadas em cada fase da vida. Nessa nova configuração, tal estruturação linear e normativa do curso da vida parece já não fazer tanto sentido quando o capitalismo industrial abre espaço para a desindustrialização e a emergência do capitalismo financeiro, em que a percepção da passagem do tempo é compreendida de uma forma diferente. A linearidade 
da passagem do tempo que reina na era industrial é substituída por vivências caracterizadas pela simultaneidade, sobreposição e compressão do tempo. A vida produtiva já não está fundamentada em saberes adquiridos no passado. Pelo contrário, espera-se cada vez mais que o trabalhador seja capaz de aprender constante e incansavelmente. Para além da educação formal, o mercado também passa a exigir formação continuada. Com isso, estudar e formar-se deixa de ser atividade exclusiva de crianças e adolescentes.

Para atender às demandas dessa sociedade pós-moderna, foi retomado como diretriz das agências internacionais multilaterais o conceito de Educação ao Longo da Vida (ELV) (IRELAND, 2019). A escolarização básica já não é mais uma credencial suficiente para garantir a estabilidade de postos em um mercado de trabalho marcado pela reestruturação produtiva e pela constante modernização tecnológica. Era necessário que as pessoas - a maioria adultos já inseridos no mundo do trabalho - aprendessem novas habilidades para sobreviver na chamada sociedade da informação (ALHEIT; DAUSIEN, 2006).

A ELV, embora seja uma questão já registrada por filósofos da Antiguidade, começou a ganhar fôlego novamente em meados dos anos 1960 na Europa (IRELAND, 2019). 0 conceito foi associado à Organização das Nações Unidas para Educação, Ciência e Cultura (Unesco), por meio dos relatórios coordenados por Edgar Faure em 1972 - década das mudanças e reestruturações nos modos de produção -, intitulado Aprender a ser, e por Jacques Delors em 1996 - década associada ao avanço do neoliberalismo nas políticas e economias ocidentais -, cujo título é Educação, um tesouro a descobrir. Ireland (2019) relata que o conceito de ELV foi baseado inicialmente em uma perspectiva humanista, pautada na educação para a cidadania e para a democracia, tida como um direito garantido pelos Estados. Hoje, no entanto, prevalece a perspectiva econômica, de uma educação orientada à competitividade e produtividade no mercado de trabalho, cuja obtenção, enquanto serviço, é de responsabilidade dos indivíduos (IRELAND, 2019).

Em grande parte dos países europeus, o acesso à educação básica já não é uma questão para os legisladores e líderes de governos. Naquele continente, a ELV procura atender às necessidades decorrentes de uma população em processo de envelhecimento e de um mercado de trabalho que exige atualizações profissionais constantes (ALHEIT; DAUSIEN, 2006). Na América Latina, especialmente no Brasil, também está em curso uma mudança demográfica e o mercado de trabalho formal aumentou suas exigências, mas a alfabetização e a educação básica universal ainda são problemas públicos não solucionados. Desse modo, uma concepção de ELV foi incorporada em 2017 à Lei de Diretrizes e Bases da Educação Nacional (BRASIL, 1996) associada à modalidade da EJA e à educação especial. Contudo, ELV e EJA não são sinônimos, sendo essa última apenas uma das dimensões da primeira (IRELAND, 2019).

Quando jovens e adultos desejam iniciar ou mesmo retomar sua trajetória escolar e/ou de formação profissional, há maior dificuldade de adaptação e acolhimento institucional. Essa dificuldade ocorre, principalmente, porque nessa fase da vida o tempo dedicado aos estudos concorre com o de outras atividades, como o trabalho e as responsabilidades 
doméstico-familiares. Em geral, nossas instituições não estão plenamente preparadas para atender às necessidades dos indivíduos que subvertem a antiga lógica de um curso de vida linear e que, em sincronia com um mundo volátil e em constante transformação tecnológica e informacional, assumem o desafio de sobrepor educação e trabalho, educação e reprodução, aposentadoria e educação, por exemplo.

Se os desafios já se colocam para aqueles que desejam ou precisam melhorar sua competitividade no mercado de trabalho, as dificuldades são ainda maiores para aqueles que chegam à vida adulta sem concluir a educação básica. Diferentemente do ensino regular para pessoas em idade escolar, a modalidade da EJA, embora prevista em lei (BRASIL, 1996), não tem a obrigatoriedade de oferta pública e gratuita assegurada para todos que dela necessitarem.

Conforme afirma Pierro (2010), o direito à educação em todas as idades e à formação continuada ao longo da vida é um consenso somente no âmbito do discurso e dos dispositivos normativos. Na prática, embora a educação de adultos já estivesse presente no país desde o final dos anos 1940, as políticas relacionadas a esse público sempre estiveram em segundo plano, sobretudo a EJA (PIERRO; HADDAD, 2015).

Há pelo menos dois desafios apontados por Ireland (2012) para que a EJA alcance maiores êxitos no Brasil. Primeiro, que essa modalidade de ensino adquira a dimensão de uma espécie de política intersetorial. Nesse ponto, o argumento do autor encontra ressonância na literatura internacional, afinal, na fase adulta, não se trata de apenas escolarizar, mas também de incorporar efetivamente uma perspectiva de ELV. A educação ao longo da vida, ainda que segundo as lentes neoliberais, permitiria diminuir desigualdades no mercado de trabalho pelo desenvolvimento de competências valorizadas na chamada sociedade do conhecimento, altamente informatizada (HARGREAVES, 2003; CASTELLS, 2007; BLOSSFELD et al., 2014).

O segundo desafio apontado por Ireland (2012) é a necessidade de determinar a demanda latente ou espontânea por vagas na EJA. Sobre esse aspecto, Di Pierro (2010, p. 954) afirma que

[...] é preciso considerar que a motivação e a mobilização para os estudos na idade adulta relacionam-se não só às exigências de formação da vida cotidiana e à quantidade e qualidade das oportunidades de atendê-las, mas também aos horizontes de mudança socioeconômica e nas estruturas de poder, o que depende de políticas participativas e redistributivas que transcendem a esfera educacional.

É sobre o aspecto quantitativo que este trabalho se dedica. A quantidade da demanda pode ser avaliada por meio de fontes de dados censitários e demográficos. Para a gestão pública dos sistemas escolares, a principal fonte de dados utilizada para estimar a demanda por vagas escolares ano a ano é o Censo Escolar, pesquisa anual levantada pelo Inep. Essa fonte permite estimar a demanda por meio do comportamento do fluxo de matrículas entre as séries, inclusive entre ciclos da EJA. Porém, por estar limitada ao registro de matrículas, essa fonte não capta as pessoas que estão fora do sistema escolar 
e que poderiam demandar vagas na educação básica, especialmente aquelas com idades não cobertas pela escolarização obrigatória.

Uma alternativa para estimar a demanda não atendida por EJA é utilizar a Pesquisa Nacional por Amostra de Domicílios (PNAD) ou mesmo o Censo Demográfico, ambos realizados pelo Instituto Brasileiro de Geografia e Estatística (IBGE). Esta é a contribuição do presente artigo. Na próxima seção, é descrita a metodologia que permite estimar a demanda por EJA no estado de São Paulo, a partir dos dados das PNAD de 1995 e 2015.

\section{Fonte de dados e método}

Utilizamos os dados das PNAD 1995 e 2015 para elaborar o modelo Profluxo (FLETCHER; RIBEIRO, 1989) e assim cumprir com o que está previsto em lei acerca de estimativas sobre uma possível demanda por vagas na EJA.

A PNAD é uma pesquisa amostral que foi a campo entre 1967 e 2015, sendo encerrada nesse último ano e sucedida pela PNAD Contínua (PNAD-C), uma pesquisa com nova metodologia de coleta de dados. A PNAD de 1995 entrevistou em São Paulo um total de 334.263 pessoas, sendo de $1 / 750$ a fração da amostragem correspondente ao estado (IBGE, 1995). A amostra paulista contou com 41.681 pessoas e 13.757 domicílios naquele ano. Em 2015, a PNAD pesquisou um total de 356.904 pessoas, sendo que a fração de amostragem do estado de São Paulo foi de $1 / 950$ e a amostra correspondeu a 40.008 pessoas e 17.291 domicílios (IBGE, 2015b).

0 modelo Profluxo foi elaborado originalmente para suprir a necessidade de se conhecerem aspectos da progressão escolar em um contexto em que não havia ampla disponibilidade dos registros escolares. Seus criadores basearam-se em modelos anteriores de fluxo escolar (THONSTAD, 1980) e utilizaram a PNAD para a construção dos parâmetros do Profluxo (FLETCHER; RIBEIRO, 1989), os quais foram aplicados à população em idade escolar. A premissa desse modelo é a de que diferentes coortes de nascimento estão sujeitas aos mesmos níveis de acesso e progressão escolar observados em um único ponto no tempo, o que permite a leitura de um pseudofluxo de pessoas ao longo das séries escolares (FLETCHER; RIBEIRO, 1989). Para cumprir com o objetivo deste estudo, aplicamos o modelo às idades mais velhas, centrando-nos na faixa de 15 a 64 anos.

Ainda que o Profluxo requeira apenas um ponto no tempo para estimar as transições de séries, comparamos os anos de 1995 e 2015, a fim de identificar a diferença no volume da população de jovens e adultos com educação básica incompleta no intervalo de duas décadas.

Nas PNAD selecionamos as seguintes variáveis: idade; frequenta escola (sim/não); curso que frequenta; série que frequenta; duração do ensino fundamental (oito ou nove anos, variável presente na PNAD 2015); e "anos de estudo" para construção do modelo. É necessário destacar que a variável derivada "anos de estudo" sofreu mudança na forma como é calculada, devido ao aumento da duração do ensino fundamental, que é gradual de oito para nove anos desde 2007 (IBGE, 2015a). Em 2015 havia ainda uma parcela de 
pessoas matriculadas no ensino fundamental com duração de oito anos. A fim de manter a comparação de "anos de estudo" com a mesma variável em rodadas anteriores da pesquisa, o IBGE (2015a, p. 40) optou por harmonizar a duração do fundamental de nove anos para oito anos:

$\mathrm{Na}$ contagem dos anos de estudo para o ensino fundamental com duração de 9 anos, a primeira série concluída com aprovação foi enquadrada em menos de 1 ano de estudo, a segunda série, em 1 ano de estudo, e assim, sucessivamente, até a nona série, classificada em 8 anos de estudo.

O Profluxo permite conhecer a transição entre séries para toda a população a partir das informações sobre aprovação e ingresso das pessoas no sistema escolar. São consideradas aprovadas as pessoas que concluíram, com aprovação, determinada série $k$. No grupo de ingressadas estão as pessoas que foram aprovadas na série $k$ somadas àquelas que ingressaram e não concluíram a mesma série $k$.

Tal como proposto por Golgher (2004), utilizamos a variável “anos de estudo" para calcular a proporção de pessoas aprovadas. Conforme indicado pelo autor, a partir de "anos de estudo", obtém-se matriz, $A(i, j)$, a partir do seguinte raciocínio: terá sido aprovado na série $i$ quem tenha pelo menos $i$ anos de estudos (GOLGHER, 2004). A matriz de aprovados, $A(i, j)$, é, por definição, o somatório de todas as pessoas que em dada idade $j$ já haviam sido aprovadas na série $i$. A proporção de aprovados, $P_{A}(i, j)$, é obtida dividindo-se o número de pessoas aprovadas em cada série, segundo a idade, pelo total de pessoas naquela idade. Ao se dividir o total em cada célula da idade $j$ pelo total da população na idade $j$, o fator associado ao crescimento populacional, não incluído no modelo, é eliminado nessa normalização (FLETCHER; RIBEIRO, 1989).

Temos então a matriz de aprovados, $A(i, j)$, e a matriz de proporção de aprovados, $P_{A}(i, j)$, por série $i$ e idade $j$ :

$A(i, j)=\sum_{k=i}^{11} E(k, j)$

$P_{A}(i, j)=\frac{1}{\sum_{k=i}^{11} E(k, j)} A(i, j)$

Onde:

$A(i, j)$ : matriz do número de aprovados em cada série $i$, segundo a idade $j$;

$E(k, j)$ : matriz do número de anos de estudo $k$ segundo a idade $j$;

$P_{A}(i, j)$ : matriz da proporção do número de aprovados na série $i$ e idade $j$.

Já a matriz de ingressados, $I(i, j)$, trata-se, na prática, também de um cumulativo de pessoas que alguma vez ingressaram em determinada série $i$, podendo ter concluído ou não essa série. 0 número de ingressados é obtido pela soma dos aprovados na série $i$, na idade $j$, com aqueles que frequentam $(F(i, j))$ a série $i$ na idade:

$I(i, j)=A(i, j)+F(i, j)$ 
Onde:

$I(i, j)$ : matriz do número de ingressados em cada série $i$, segundo a idade $j$;

$F(i, j)$ : matriz do número de pessoas que frequentam a série $i$, na idade $j$.

A matriz daqueles que frequentavam escola em 2015 também foi ajustada, de modo que quem cursava o primeiro ano do ensino fundamental com duração de nove anos não foi considerado no cômputo. Assumimos, tal como o procedimento de harmonização adotado pelo IBGE, que aqueles que cursavam o segundo ano do ensino fundamental de nove anos correspondiam à antiga primeira série do ensino fundamental com duração de oito anos. No entanto, essas perdas não se refletem significativamente no modelo, uma vez que, para 2015, nas idades analisadas ( 15 a 64 anos, $n=31.480 .761$ ), havia 5.595 pessoas ( $0,02 \%$ do total da população nessa faixa etária) computadas como estando frequentando o primeiro ano do ensino fundamental com duração de nove anos.

\section{Resultados e discussão}

As saídas do modelo indicam que os jovens e adultos de 2015 tinham um nível de escolaridade mais elevado do que os jovens e adultos de 1995. 0 Gráfico 1 mostra, para as idades analisadas, as curvas das proporções de pessoas que ingressaram no ensino fundamental e daquelas que concluíram o ensino médio nos dois anos observados.

\section{GRÁFICO 1}

Proporção de pessoas ingressadas e aprovadas na educação básica, segundo a idade Estado de São Paulo - 1995-2015

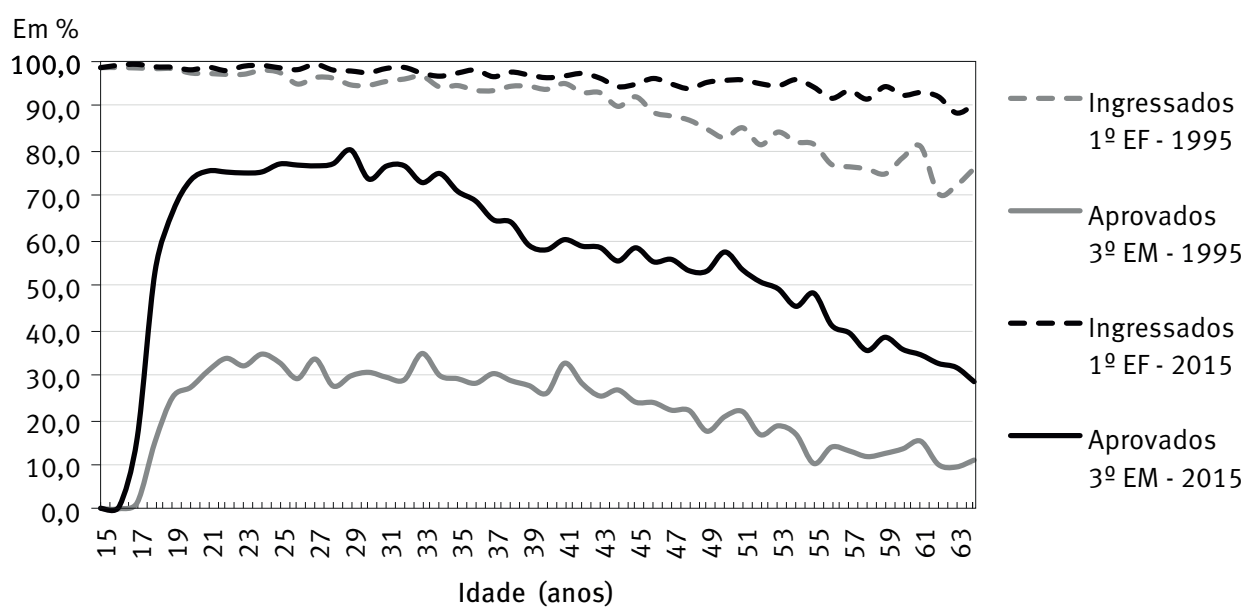

Fonte: IBGE. Pesquisa Nacional por Amostra de Domicílios - PNAD 1995 e 2015.

Deve-se fazer a ressalva de que, para a população entre 15 e 18 anos, as pessoas poderiam estar frequentando a escola, sobretudo a etapa do ensino médio. Se um adolescente de 18 anos encontra-se cursando o último ano do ensino médio, seguindo os critérios do Inep, ele não se encontra em atraso escolar, pois se assume que ele pode ter iniciado o ano 
letivo com 17 anos (INEP, 2004). Contudo, aos 19 anos a pessoa já teria idade suficiente para ter completado, em fase, a educação básica. Em 1995, 1 /4 dos adolescentes nessa idade tinha concluído o ensino médio; em 2015, 75\% deles haviam completado essa etapa da escolaridade. Esse dado sugere que a trajetória escolar dos adolescentes em 2015 teve menos rupturas do que a de seus homólogos em 1995. Em contrapartida, apesar dos avanços, a leitura necessária para estimar a demanda por EJA é a de que $25 \%$ dos jovens de 19 anos, em 2015, não haviam completado a educação básica.

As curvas representadas no Gráfico 1 indicam as condições de escolarização às quais estavam expostas as coortes mais velhas. Isso fica evidente em 1995 e parece ter sido suavizado em 2015. Praticamente todas as pessoas nas idades observadas chegaram a ingressar no ensino fundamental, em 2015, e a curva de ingressados começa a se distanciar da linha dos $100 \%$ a partir do marco de 40 anos de idade. Ou seja, pessoas que em 2015 eram nascidas antes de 1975 denotam haver sofrido maior dificuldade de acesso à escola do que as coortes nascidas depois desse ano. Em 1995, a curva de ingressados se afasta dos $100 \%$ a partir de 25 anos de idade, reforçando a leitura anterior, de que pessoas nascidas antes da década de 1970 parecem ter tido mais dificuldade de acesso à primeira série do ensino fundamental.

Além dessas interpretações, vale destacar a heterogeneidade dessa possível demanda por EJA, pelo menos no que diz respeito às idades. Não se trata de um público concentrado nas idades muito mais velhas, embora o estoque cresça conforme avançam os grupos etários.

A Tabela 1 retrata o número de pessoas em 1995 e 2015, por grupo etário, que estariam aptas a ingressar em cada um dos ciclos ${ }^{1}$ da educação básica. Em termos relativos, em 1995, 62\% da população de 15 a 64 anos não tinha completado a educação básica. Em 2015, esse percentual cai para 30\%. Trata-se de uma estimativa do estoque de pessoas para cada ciclo, pois a modalidade EJA provê o certificado de conclusão das etapas do fundamental e/ou médio a partir da compressão do tempo de duração desses ciclos da educação básica. Em termos absolutos, houve diminuição de uma possível demanda pelo ensino fundamental. Contudo, observamos um aumento do estoque de pessoas aptas a ingressar no ensino médio em 2015 em comparação a 1995.

Além dos números absolutos, apresentamos também o ritmo de crescimento do volume desse estoque por meio das taxas de crescimento no período 1995-2015, por grupo etário e por ciclo (Tabela 2).

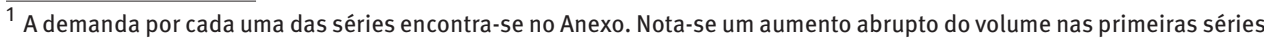
de cada ciclo. Isso pode sugerir certa dificuldade de permanência escolar na transição entre os ciclos da educação básica.
} 
TABELA 1

Estoque de pessoas aptas a ingressar nos ciclos da educação básica, por grupos de idade Estado de São Paulo - 1995-2015

\begin{tabular}{|c|c|c|c|c|c|c|}
\hline \multirow{2}{*}{ Ciclos de ensino } & \multicolumn{6}{|c|}{ Grupos de idade } \\
\hline & 15 a 18 & 19 a 24 & 25 a 29 & 30 a 34 & 35 a 39 & 40 a 44 \\
\hline \multicolumn{7}{|l|}{1995} \\
\hline Fundamental I & 136.002 & 267.081 & 331.586 & 379.444 & 383.574 & 421.868 \\
\hline Fundamental II & 481.999 & 1.016 .659 & 916.462 & 929.821 & 958.694 & 881.481 \\
\hline Médio & 155.609 & 565.307 & 502.692 & 480.979 & 403.589 & 274.679 \\
\hline Total educação básica & 773.610 & 1.849 .047 & 1.750 .740 & 1.790 .244 & 1.745 .857 & 1.578 .028 \\
\hline Total de pessoas no grupo etário & 2.701 .406 & 3.463 .404 & 2.745 .749 & 2.765 .436 & 2.629 .830 & 2.319 .825 \\
\hline \multicolumn{7}{|l|}{2015} \\
\hline Fundamental I & 13.484 & 39.232 & 43.317 & 76.247 & 111.691 & 181.668 \\
\hline Fundamental II & 90.733 & 204.847 & 189.289 & 300.957 & 492.244 & 635.244 \\
\hline Médio & 135.400 & 539.516 & 428.746 & 430.124 & 460.241 & 491.867 \\
\hline Total educação básica & 239.617 & 783.595 & 661.352 & 807.328 & 1.064 .176 & 1.308 .779 \\
\hline Total de pessoas no grupo etário & 2.804 .751 & 4.011 .177 & 3.331 .987 & 3.618 .324 & 3.432 .221 & 3.380 .268 \\
\hline \multirow{2}{*}{ Ciclos de ensino } & \multicolumn{4}{|c|}{ Grupos de idade } & \multirow{2}{*}{\multicolumn{2}{|c|}{ Total por ciclo }} \\
\hline & 45 a 49 & 50 a 54 & 55 a 59 & 60 a 64 & & \\
\hline \multicolumn{7}{|l|}{1995} \\
\hline Fundamental I & 451.391 & 460.628 & 481.216 & 429.694 & \multicolumn{2}{|c|}{3.742 .124} \\
\hline Fundamental II & 689.467 & 525.670 & 401.115 & 313.705 & \multicolumn{2}{|c|}{7.115 .073} \\
\hline Médio & 196.884 & 110.338 & 78.950 & 59.349 & \multicolumn{2}{|c|}{2.828 .376} \\
\hline Total educação básica & 1.337 .742 & 1.096 .636 & 961.281 & 802.748 & \multicolumn{2}{|c|}{13.685 .573} \\
\hline Total de pessoas no grupo etário & 1.837 .640 & 1.464 .475 & 1.180 .009 & 977.073 & \multicolumn{2}{|c|}{22.084 .847} \\
\hline \multicolumn{7}{|l|}{2015} \\
\hline Fundamental I & 219.115 & 261.138 & 328.425 & 354.607 & \multicolumn{2}{|c|}{1.615 .440} \\
\hline Fundamental II & 540.318 & 627.017 & 585.967 & 595.221 & \multicolumn{2}{|c|}{4.171 .104} \\
\hline Médio & 516.175 & 446.475 & 249.534 & 113.896 & \multicolumn{2}{|c|}{3.676 .574} \\
\hline Total educação básica & 1.275 .608 & 1.334 .630 & 1.163 .926 & 1.063 .724 & \multicolumn{2}{|c|}{9.463 .118} \\
\hline Total de pessoas no grupo etário & 3.121 .570 & 3.056 .449 & 2.558 .068 & 2.165 .946 & \multicolumn{2}{|c|}{31.480 .761} \\
\hline
\end{tabular}

Fonte: IBGE. Pesquisa Nacional por Amostra de Domicílios - PNAD 1995 e 2015.

TABELA 2

Taxas de crescimento do estoque de pessoas aptas a ingressar nos ciclos da educação básica, por grupos de idade

Estado de São Paulo - 1995/2015

\begin{tabular}{|c|c|c|c|c|c|c|c|c|c|c|c|}
\hline \multirow{3}{*}{$\begin{array}{l}\text { Ciclos de } \\
\text { ensino }\end{array}$} & \multicolumn{11}{|c|}{ Em porcentagem } \\
\hline & \multicolumn{10}{|c|}{ Grupos de idade } & \multirow{2}{*}{$\begin{array}{c}\text { Total por } \\
\text { ciclos }\end{array}$} \\
\hline & 15 a 18 & 19 a 24 & 25 a 29 & 30 a 34 & 35 a 39 & 40 a 44 & 45 a 49 & 50 a 54 & 55 a 59 & 60 a 64 & \\
\hline Fundamental I & $-4,29$ & $-4,06$ & $-4,14$ & $-3,81$ & $-3,38$ & $-2,71$ & $-2,45$ & $-2,06$ & $-1,51$ & $-0,83$ & $-2,71$ \\
\hline Fundamental II & $-3,87$ & $-3,80$ & $-3,78$ & $-3,22$ & $-2,32$ & $-1,33$ & $-1,03$ & 0,92 & 2,19 & 4,27 & $-1,97$ \\
\hline Médio & $-0,62$ & $-0,22$ & $-0,70$ & $-0,50$ & 0,67 & 3,77 & 7,72 & 14,51 & 10,29 & 4,38 & 1,43 \\
\hline $\begin{array}{l}\text { Total educação } \\
\text { básica }\end{array}$ & $-3,29$ & $-2,74$ & $-2,96$ & $-2,61$ & $-1,86$ & $-0,81$ & $-0,22$ & 1,03 & 1,00 & 1,55 & $-1,47$ \\
\hline Total grupo etário & 0,18 & 0,75 & 1,02 & 1,47 & 1,45 & 2,18 & 3,33 & 5,18 & 5,56 & 5,79 & 2,03 \\
\hline
\end{tabular}

Fonte: IBGE. Pesquisa Nacional por Amostra de Domicílios - PNAD 1995 e 2015. 
Para aqueles que ingressaram no sistema escolar, há uma dificuldade de progredir entre os ciclos da educação básica, conforme se observa nas linhas referentes aos primeiros anos dos anos finais do fundamental (antigo ginásio) e do ensino médio (antigo colegial). Os aspectos da progressão escolar, na transição do ensino fundamental para o ensino médio, estão ilustrados no Gráfico 2, cuja distância entre as linhas contínuas (aprovados no último ano do ensino fundamental) e pontilhadas (ingressados no primeiro ano do ensino médio) representa a evasão observada em 1995 e 2015.

\section{GRÁFICO 2}

Proporçãolde aprovados na última série do ensino fundamental e de ingressados na primeira série do ensino médio, segundo a idade

Estado de São Paulo - 1995-2015

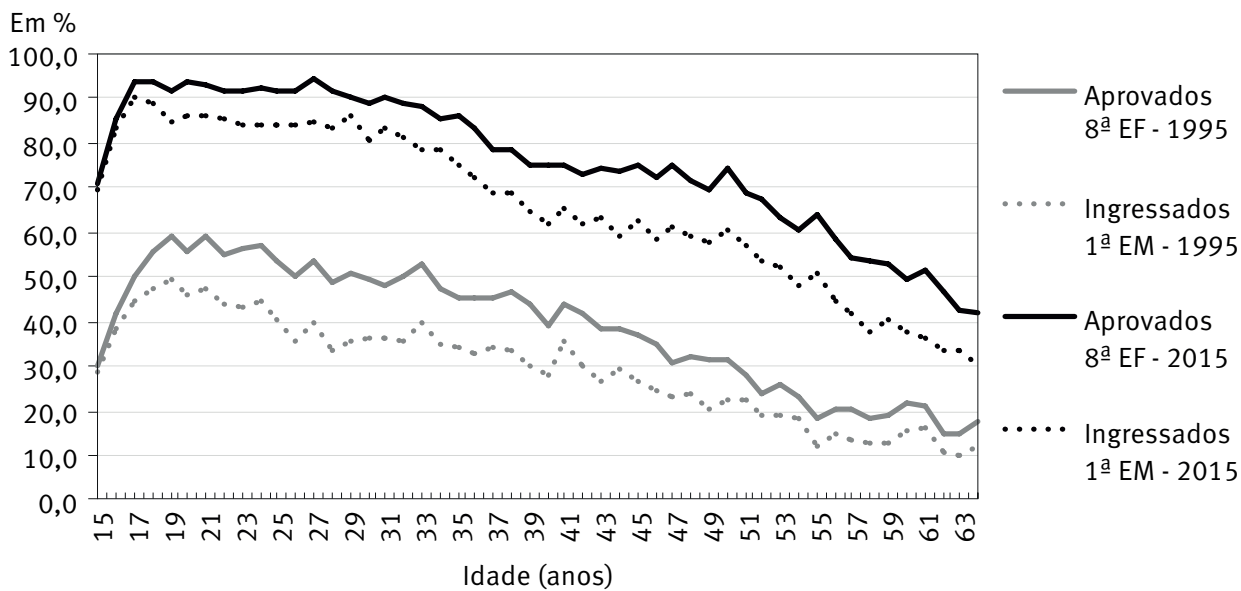

Fonte: IBGE. Pesquisa Nacional por Amostra de Domicílios - PNAD 1995 e 2015.

A evasão é caracterizada quando a pessoa não se matricula no ano letivo seguinte, seja na mesma série, seja na série seguinte (INEP, 2004). Ao utilizar a PNAD, a evasão é captada indiretamente, pelo fato de que a pessoa, mesmo tendo credencial para seguir os estudos, não ingressou na série seguinte. No Gráfico 2, observa-se que, embora o fenômeno persista, a proporção de evadidos diminuiu ao longo das duas décadas estudadas. Esses dados sugerem que é necessária uma ação que aumente as chances de uma pessoa continuar seus estudos quando completa o ensino fundamental. É conhecido, no entanto, o fato de que, quando ocorre a transição dessas etapas, os adolescentes encontram-se geralmente nas idades entre 14 e 16 anos, que é quando, pelo menos em termos legais, pode-se começar a trabalhar (BRASIL, 1988). A entrada precoce no mercado de trabalho, sem a escolarização mínima obrigatória, acumula o déficit educacional - o que poderia influenciar a demanda por EJA no futuro.

A dificuldade de sobrevivência à transição entre os ciclos fica evidente no Gráfico 3, que traz as curvas da proporção de pessoas que, em 2015, haviam concluído cada uma das séries que compõem os ensinos fundamental e médio. 
GRÁFICO 3

Proporção de aprovados em cada série da educação básica, segundo a idade Estado de São Paulo - 2015

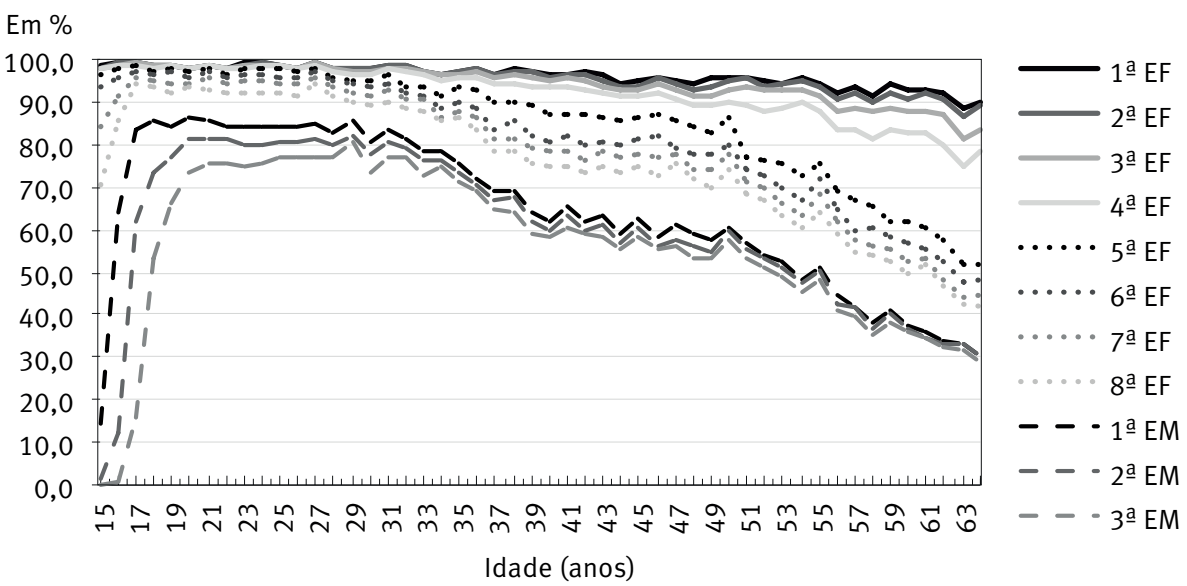

Fonte: IBGE. Pesquisa Nacional por Amostra de Domicílios - PNAD 2015.

No Gráfico 3, observamos que os grupos de linhas que se formam correspondem aos três ciclos: anos iniciais do fundamental (linhas contínuas), anos finais do fundamental (linhas pontilhadas) e ensino médio (linhas tracejadas). Esse agrupamento sugere que a sobrevivência à transição entre os ciclos é mais difícil do que as transições entre séries de um mesmo ciclo, especialmente para as coortes mais velhas. Esse dado sugere ainda que políticas e ações que visem à escolarização da população adulta precisam considerar essa especificidade da dinâmica dentro do sistema escolar, além da ampla heterogeneidade etária do público-alvo.

\section{Conclusão}

Este estudo assume a educação como um direito de todos, independentemente de sua idade. A metodologia aqui aplicada procura, de certa maneira, cumprir uma determinação já fixada com força de lei, de dar a conhecer qual é o estoque de pessoas sem educação básica completa. Este é um ponto que merece atenção de gestores e pesquisadores, mas principalmente de instituições que contem com maior nível organizacional e guardem as competências necessárias para realizar esse levantamento e gerenciar a disponibilidade dessa informação.

Os resultados aqui apresentados indicam que há uma parcela importante da população adulta, residente no estado de São Paulo, a qual segue com a educação básica incompleta. Ela conforma um estoque que pode ser convertido em demanda potencial para a EJA. 0 volume desse estoque, por sua vez, pode ser estimado por meio de fonte e método demográficos. Assim, buscou-se, por meio da aplicação do modelo Profluxo, estimar o número de jovens e adultos que não concluíram a educação básica e que constituem, portanto, 
um estoque invisível para a maioria das políticas educacionais. Nesse sentido, o modelo elaborado há 30 anos mostra-se útil para analisar os avanços educacionais da população, bem como os seus desafios, a partir de fontes de dados demográficos.

Os achados deste estudo reforçam dois pontos: a importância das informações sobre educação para toda a população e não apenas para aqueles inseridos no sistema escolar; e a relevância desse tipo de informação em fontes demográficas para subsidiar a formulação de políticas públicas educacionais mais acuradas.

Há que se reconhecer que existe uma dívida educacional para com essas pessoas. Todavia, para além do direito de cada cidadão à educação, deve-se ressaltar o potencial multiplicador e a reverberação da escolarização dos adultos no interior das famílias. Se os adultos se escolarizam, isso pode funcionar como inspiração, exemplo e apoio para os membros mais jovens de sua rede de relacionamentos próximos. Estimula-se, portanto, a formação de um círculo virtuoso no âmbito educacional.

Espera-se, humildemente, que estudos como esse despertem a atenção para o volume da população a ser contemplada pelas políticas educacionais, bem como para as idades e séries/anos mais críticos para o abandono e a retenção escolar. Assim, compreendendo em que períodos ocorrem as maiores dificuldades de progressão escolar, é possível identificar momentos oportunos para intervenções. Compartilha-se da visão de que quanto mais cedo os cidadãos puderem se escolarizar, melhor. Mas, quando isso não ocorre, é preciso garantir que se possa usufruir deste direito.

\section{Referências}

ALHEIT, P.; DAUSIEN, B. Processo de formação e aprendizagens ao longo da vida. Educação e Pesquisa, São Paulo, v. 32, n. 1, p. 177-197, 2006.

BERCOVICH, A.; MADEIRA, F. Descontinuidades demográficas no Brasil e no Estado de São Paulo. In: ENCONTRO NACIONAL DE ESTUDOS POPULACIONAIS, 7., 1990, Caxambu, MG. Anais [...]. Belo Horizonte: Abep, v. 2, 1990.

BLOSSFELD, H-P et al. (ed.). Adult learning in modern societies: an international comparison from a life-course perspective. [S.l.]: Edward Elgar Publishing, 2014.

BRASIL. Presidência da República. Constituição da República Federativa do Brasil de 1988. Brasília, 1988.

BRASIL. Presidência da República. Lei n. 9394 de 20 de dezembro de 1996. Estabelece as diretrizes e bases da educação nacional. Brasília, 1996.

BRASIL. Conselho Nacional de Educação. Resolução CNE/CEB n. 1, de 5 de julho de 2000. Estabelece as diretrizes curriculares nacionais para educação de jovens e adultos. Brasília, 2000.

BRASIL. Presidência da República. Lei n. 12.796, de 4 de abril de 2013. Altera a Lei n. 9.394, de 20 de dezembro de 1996, que estabelece as diretrizes e bases da educação nacional, para dispor sobre a formação dos profissionais da educação e dar outras providências. Brasília, 2013.

CAMARANO, A. A. Living longer: are we getting older or younger for longer? Vibrant Virtual Brazilian Anthropology, Brasília, v. 13, n. 1, p. 155-175, 2016. 
CAMARANO, A. A. et al. Do nascimento à morte: principais transições. In: CAMARANO, A. A. (org.). Transição para a vida adulta ou vida adulta em transição? Rio de Janeiro: Ipea, 2006.

CASSIO, F. L.; CROCHIK, L.; PIERRO, M. C.; STOCO, S. Demanda social, planejamento e direito à educação básica: uma análise da rede estadual de ensino paulista na transição 2015-2016. Educação e Sociedade, Campinas, v. 37, n. 137, p. 1089-1119, 2016.

CASTELLS, M. A sociedade em rede. São Paulo: Paz e Terra, 2007.

CHAMBOREDON, J. C. Adolescence et post-adolescence: la "juvénisation". Remarques sur les transformations recentes des limites et de la définition sociale de la jeunesse. In: ALLEÓN, A. M.; MORVAN, O.; LEBOVICI, S. Adolescence terminée, adolescence interminable. Paris: PUF, 1985. p. 13-28.

CORTI, A. P. O. À deriva: um estudo sobre a expansão do ensino médio no estado de São Paulo (1991-2003). 2015. 300f. Tese (Doutorado em Educação) - Faculdade de Educação, Universidade de São Paulo, São Paulo, 2015.

DEBERT, G. G. Velhice e o curso da vida pós-moderno. Revista USP, n. 42, p. 70-83, 1999.

FLETCHER, P.; RIBEIRO, S. C. Modeling education system performance with demographic data: in introduction to the Profluxo Model. Paris: Unesco, 1989.

FRITH, U. Neuroscience: implications for education and lifelong learning. Integrating Science and Practice, v. 3, n. 1, p. 7-10, 2013.

GOLGHER, A. B. Modelo Profluxo e indicadores derivados. In: RIOS-NETO, E. L. G.; RIANI, J. L. R. (org.). Introdução à demografia da educação. Rio de Janeiro: Abep, 2004. p. 159-208.

GRACIANO, M.; LUGLI, R. G. Educação de jovens e adultos na diversidade e inclusão: algumas reflexões. In: GRACIANO, M.; LUGLI, R. G. (org.). Direitos, diversidade, práticas e experiências educativas na educação de jovens e adultos. São Paulo: Alameda, 2017.

HARGREAVES, A. 0 ensino na sociedade do conhecimento: a educação na era da insegurança. Porto: Porto Editora, 2003.

IBGE - Instituto Brasileiro de Geografia e Estatística. Pesquisa Nacional por Amostra de Domicílios: n. 26 - São Paulo e Região Metropolitana de São Paulo. Rio de Janeiro, v. 17, 1995.

IBGE - Instituto Brasileiro de Geografia e Estatística. Pesquisa Nacional por Amostra de Domicílios: notas metodológicas. Rio de Janeiro, 2015 a.

IBGE - Instituto Brasileiro de Geografia e Estatística. Pesquisa Nacional por Amostra de Domicílios: síntese de indicadores 2015. Rio de Janeiro, 2015b.

INEP - Instituto Nacional de Estudos e Pesquisas Educacionais Anísio Teixeira. Dicionário de indicadores educacionais. Formas de cálculo. Brasília, 2004.

IRELAND, T. D. Educação de jovens e adultos como política pública no Brasil (2004-2010): os desafios da desigualdade e da diversidade. Rizoma Freiriano, n. 13, 2012.

IRELAND, T. D. Educação ao longo da vida: aprendendo a viver melhor. Sisyphus - Journal of Education, v. 7, n. 2, p. 48-64, 2019.

MACMILLAN, R. The structure of the life course: classic issues and current controversies. Advances in Life Course Research, New York, v. 9, p. 3-24, 2005.

MACHADO, M. M. A educação de jovens e adultos no Brasil pós-Lei n. 9394/96: a possibilidade de constituir-se como política pública. Em Aberto, Brasília, v. 22, n. 82, p. 17-39, 2009. 
MORAES, C. S. V. Educação de jovens e adultos trabalhadores de qualidade: regime de colaboração e sistema nacional de educação. Educação e Sociedade, Campinas, v. 34, n. 124, p. 979-1001, 2013.

MOTTA, A. B. Gênero, família e fases do ciclo de vida. Caderno CRH, Salvador, n. 29, p. 13-20, 1998.

PANTOJO, B.; SALOMÃO, L. A.; CASTRO, M. N. P.; MARTINS, M.; BATISTA FILHO, O. N. Escolas estaduais com uma única etapa de atendimento e seus reflexos no desempenho dos alunos. São Paulo: Coordenadoria de Informação, Monitoramento e Avaliação Educacional (Cima)/ SEE-SP, agosto 2015.

PIERRO, M. C. A educação de jovens e adultos no plano nacional de educação: avaliação, desafios e perspectivas. Educação e Sociedade, Campinas, v. 31, n. 112, p. 939-959, 2010.

PIERRO, M. C.; HADDAD, S. Transformações nas políticas de educação de jovens e adultos no Brasil no início do terceiro milênio: uma análise das agendas nacional e internacional. Cadernos Cedes, Campinas, v. 35, n. 96, p. 197-217, 2015.

PIERRO, M. C. (org.); KUHN, A.; CRUZ, B. M.; TSUCHIYA, B. K.; BATISTÃO, M. B. Um estudo sobre centros públicos de educação de jovens e adultos no estado de São Paulo. São Paulo: Feusp, Fapesp, 2017.

PIERRO, M. C.; CATELLI JR., R. A construção dos direitos dos jovens e adultos à educação na história brasileira recente. In: GRACIANO, M.; LUGLI, R. G. (org.). Direitos, diversidade, práticas e experiências educativas na educação de jovens e adultos. São Paulo: Alameda, 2017.

SEADE - Fundação Sistema Estadual de Análise de Dados. Levantamento sobre a evolução das matrículas no ensino básico estadual. São Paulo, 2015.

SÃO PAULO (Estado). Decreto n. 61.672 de 30 de novembro de 2015. Disciplina a transferência dos integrantes dos Quadros de Pessoal da Secretaria da Educação e dá providências correlatas. Diário Oficial do Estado de São Paulo, São Paulo, v. 125, n. 222, 2015.

SHEEHY, G. Prologue: oh, pioneers! In: SHEEHY, G. New passages: mapping your life across time. New York: New Ballantine Book, 1995. p. 3-22.

THONSTAD, T. Analysing and projecting school enrolment in developing countries: a manual of methodology. Paris: Unesco, 1980. (Statistical Reports and Studies, n. 24).

\section{Sobre as autoras}

Flávia Vitor Longo é demógrafa, doutora em demografia pela Universidade Estadual de Campinas (Unicamp).

Joice Melo Vieira é demógrafa, doutora em demografia pela Universidade Estadual de Campinas (Unicamp). Pesquisadora do Núcleo de Estudos de População “Elza Berquó" e professora do Instituto de Filosofia e Ciências Humanas, ambos da Unicamp.

\section{Endereço para correspondência}

Flávia Vitor Longo

Av. Albert Einstein, 1300, Cidade Universitária Zeferino Vaz 13083-852 - Campinas-SP, Brasil 
Joice Melo Vieira

Av. Albert Einstein, 1300, Cidade Universitária Zeferino Vaz

13083-852 - Campinas-SP, Brasil

\section{Abstract}

Estimation of population stock to demand education for youngsters and adults in the State of São Paulo in 1995 and 2015

The Guidelines and Bases for National Education Law establishes that it is the Federation's duty to annually register, not only school-age children and adolescents, but also youngsters and adults who have not completed basic education. The aim of this study is to measure the stock of youngsters and adults ( 15 to 64 years old) with incomplete basic education in the State of São Paulo and to estimate the demand for education should all of them return to school. The methodology is based on data from the 1995 and 2015 National Household Sample Survey and on the application of the Profluxo model. Results indicate that the main narrowing in the system occurs in the transition from one educational cycle to another. The demand persists, especially in the first years of each cycle of basic education, although in a lower volume in 2015, compared to 1995.

Keywords: State of São Paulo. Public education policies. EJA. PNAD. Profluxo.

\section{Resumen}

Estimativa del stock de población apta para demandar educación de jóvenes y adultos en el estado de San Pablo en 1995 y 2015

La Ley de Bases y Lineamientos de Educación Nacional establece que es deber de la Republica Federativa de Brasil registrar anualmente no solo niños, niñas y adolescentes en edad escolar, sino también a jóvenes y adultos que no hayan completado la educación básica. El objetivo de este estudio es medir el stock de jóvenes y adultos (15 a 64 años) con educación básica incompleta en el estado de San Pablo y estimar la demanda por nivel educativo en caso de que regresaran a los bancos escolares. La metodología se basa en datos de la Encuesta Nacional de Hogares por Muestra de 1995 y de 2015 y en la aplicación del modelo Profluxo. Los resultados indican que los principales estrechamientos del sistema se encuentran en la transición de un ciclo educativo a otro. La demanda persiste, especialmente en los primeros años de cada ciclo de educación básica, aunque en un volumen menor en 2015 respecto a 1995.

Palabras clave: Estado de San Pablo. Políticas de educación pública. EJA. PNAD. Profluxo. 


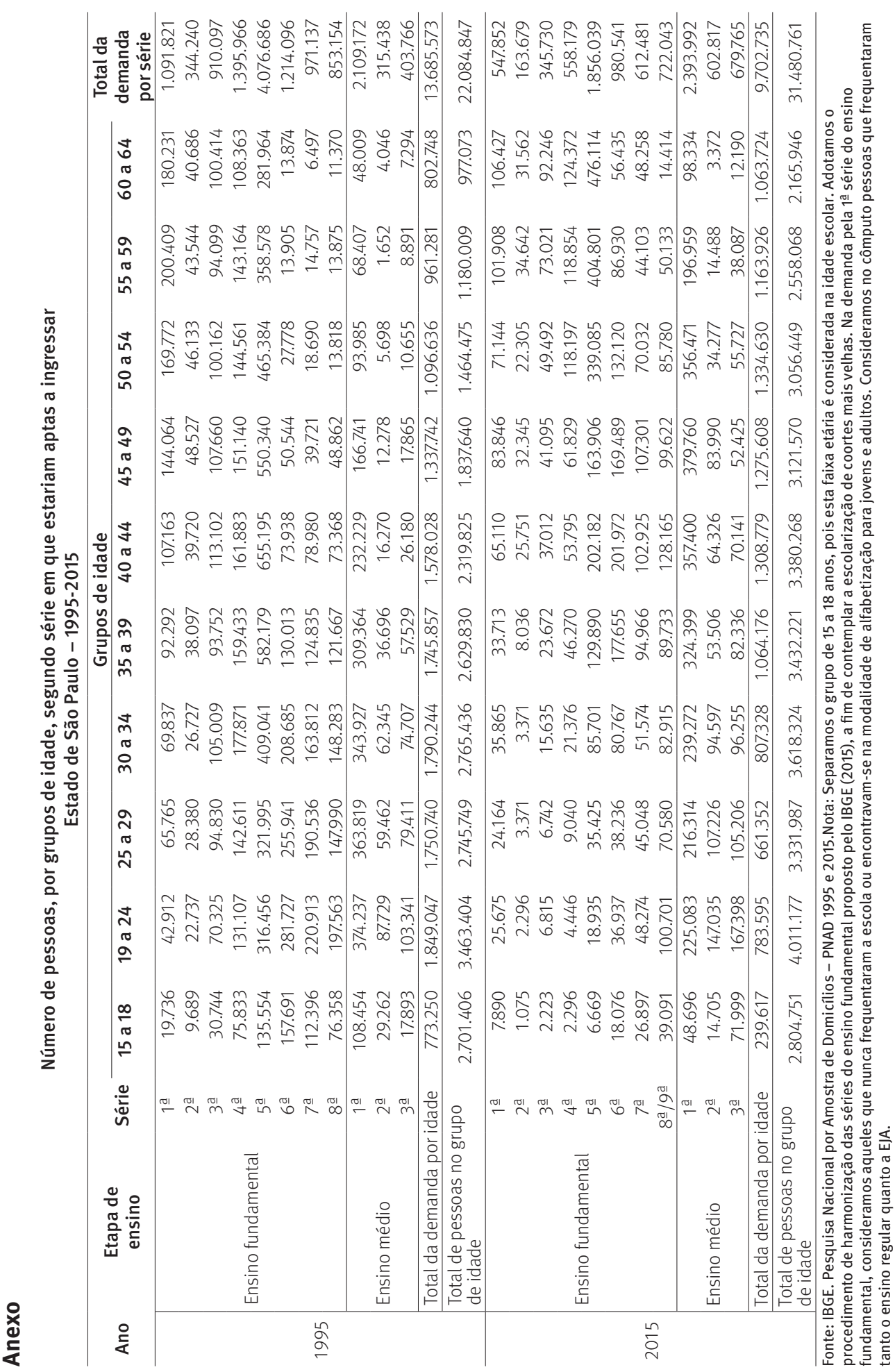

